University of Nebraska - Lincoln

DigitalCommons@University of Nebraska - Lincoln

3-15-2013

Health care and the cross-section of US stock returns

Brian C. Payne

John Geppert

Follow this and additional works at: https://digitalcommons.unl.edu/financefacpub

Part of the Finance and Financial Management Commons

This Article is brought to you for free and open access by the Finance Department at DigitalCommons@University of Nebraska - Lincoln. It has been accepted for inclusion in Finance Department Faculty Publications by an authorized administrator of DigitalCommons@University of Nebraska - Lincoln. 


\title{
Health care and the cross-section of US stock returns
}

\author{
Brian C. Payne $\cdot$ John M. Geppert
}

Published online: 15 March 2013

(C) Springer Science+Business Media New York 2013

\begin{abstract}
Health care costs represent a large and growing component of business and consumer expenditures in the US. Medical inflation represents these costs, and it differs from aggregate inflation and other market factors with respect to its rate of growth, statistical properties and the extent to which it can be hedged by households and firms. Using multiple model specifications for the 25-year period from 1985 to 2009 , we find medical inflation is robustly priced in the cross-section of US stock returns. It commands a risk premium of between 31 and 51 basis points per annum per unit change in beta. Medical inflation is also unique in that it represents the only inflationary component that robustly explains the cross-section of stock returns in this manner and is not subsumed by other common factors in the literature. These results quantify the health care industry's unique and significant role in the US economy and stock market, further rationalizing the substantial attention this industry receives.
\end{abstract}

Keywords Health care $\cdot$ Asset returns $\cdot$ Risk factors

JEL Classification $\mathrm{G} 10 \cdot \mathrm{G} 11 \cdot \mathrm{G} 32$

\section{Introduction}

Modern asset pricing theory seeks to find underlying economic, or risk, factors that account for the temporal and cross-sectional variation in asset returns. The literature has progressed from the aggregate market return as the only relevant factor (Sharpe 1964, and Lintner 1965, CAPM), to multifactor models based on the Ross (1976)

B. C. Payne $(\square)$

Department of Management, U.S. Air Force Academy, 2354 Fairchild Dr, Colorado Springs, CO 80840, USA

e-mail: brian.payne@usafa.edu

J. M. Geppert

Department of Finance, University of Nebraska-Lincoln, 229 CBA, Lincoln, NE 68588-0490, USA

e-mail: jgeppert1@unl.edu 
arbitrage pricing theory (APT) or consumption (C-CAPM and ICAPM). Considering health care costs as one such risk factor, we find medical inflation contributes to the cross-section of stock returns even in the presence of previously considered factors.

The literature relating stock returns to aggregate inflation dates as early as Bodie (1976), who finds an anomalous negative relation between stock returns and inflation. ${ }^{1}$ Fama (1981) and Geske and Roll (1983) argue that the observed relation between inflation and stock returns is spurious. In contrast, Modigliani et al. (1979) offer a real causal link between inflation and asset returns based on investor mispricing.

Incorporating US health care costs (i.e., medical inflation) into a factor pricing model is materially different than previous research that has used aggregate inflation. Medical inflation acts as a priced factor because of its unique impact on individual consumption and firm cash flows. In the context of modern asset pricing theory, investors attempt to smooth their consumption. Assets with returns that covary positively with consumption are risky, while those that covary negatively with consumption act as hedges. Within the context of the ICAPM, investors demand assets with returns that covary positively with medical expenditures, and these assets will command a lower expected return based on their hedging function. Traditionally, consumption is modeled at the aggregate level; however, medical care consumption warrants special treatment from other items in the consumption basket because of its potential catastrophic impact on individuals and its high demand inelasticity. Rather than use changes in medical consumption expenditures directly, we proxy medical care consumption with the medical care component of the consumer price index (CPI). Using the price index data in place of medical expenditures has the advantage that medical inflation data are available monthly, which corresponds to the frequency of our return data. Comparing the OECD figures for annual per person health care expenditures to annual medical inflation figures supports this proxy decision. Between 1985 and 2008, per person health care expenditures in the US increased approximately $6 \%$ annually; annual medical inflation increased $5 \%$ annually over the same period. Thus the consumed quantity of medical expenditures changes at approximately the same rates as medical inflation, and indeed the two annual series are highly correlated with a Pearson value exceeding 0.80 .

As for the justification to separate medical inflation from aggregate inflation, we note medical inflation is distinct from aggregate inflation and its other components in its degree, its statistical properties, its ability to be hedged, and its impact on consumers and firms. The extreme level of the medical component of the CPI is illustrated in Fig. 1. Although we recognize levels are not of ultimate interest, this figure demonstrates the marked divergence of medical goods from others in the consumption basket during the 25-year study period.

The medical component of the Consumer Price Index (CPI) breaks from the other components of the CPI in approximately 1985. The CPI components in Fig. 1 currently represent almost $80 \%$ of the aggregate CPI, with the Medical component representing $6.39 \%$, Housing $43.42 \%$, Food $15.76 \%$, and Transportation $15.31 \%{ }^{2}$

\footnotetext{
${ }^{1}$ Other studies relating aggregate inflation and stock returns include Fama and Schwert (1977) and Schwert (1981) for short-run relationships and Boudoukh and Richardson (1993) for long-term relationships.

${ }^{2}$ While medical expenditures represent only $6.39 \%$ of expenditures on average they are highly skewed, with some individuals incurring catastrophic expenditures. The possibility of these extreme realizations is one of the distinguishing characteristics of medical expenditures.
} 


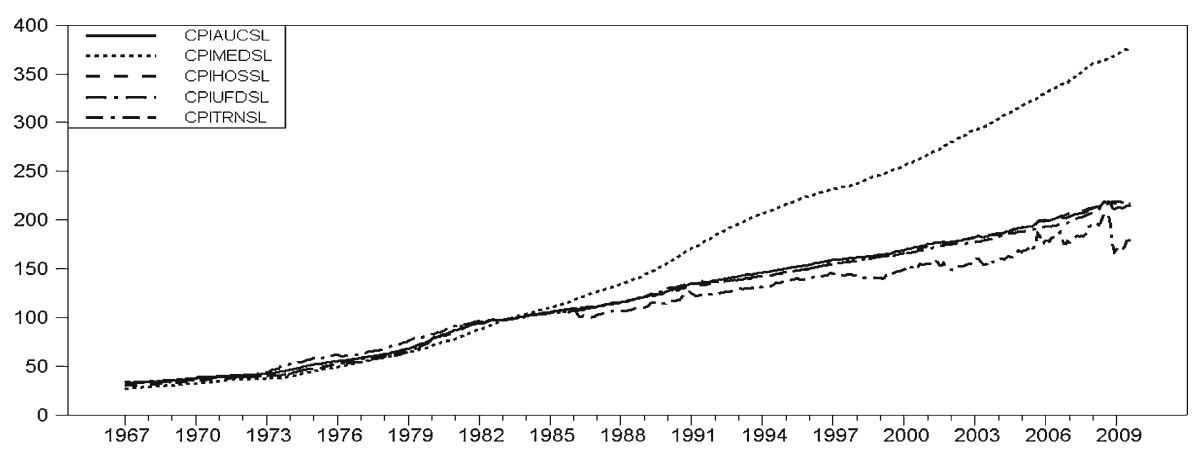

Fig. 1 Consumer Price Index (CPI) levels. This Figure shows the monthly index levels for the aggregate CPI (CPIAUCSL) and its major components: Medical CPI (CPIMEDSL), Housing CPI (CPIHOSSL), Food CPI (CPIUFDSL), and Transportation CPI (CPITRNSL) from January 1967 to August 2009. Data comes from the St. Louis Federal Reserve Economic Database (FRED)

Medical inflation also differs from other items in the CPI basket in terms of individuals' and firms' ability to manage the associated costs. Certainly the use of medical insurance allows consumers to partially "smooth" their consumption of medical expenses over time. However, the empirical evidence on personal bankruptcies suggests that even with insurance medical expenses are unique and cannot be fully pooled. For example, Himmelstein et al. (2009) find $62 \%$ of personal bankruptcies filed in 2007 were linked to medical expenses even though nearly $80 \%$ of those filing for bankruptcy had health insurance. This rate of medical-cost-induced personal bankruptcies has increased by almost $50 \%$ since 2001 .

The statistical properties and elasticities of medical expenses distinguish it from other components of the CPI basket. The five components of Housing, Food, Energy, Education and Transportation account for over $85 \%$ of the CPI. Unlike Food and Energy, which have price movements that contain a large transitory component, shocks to medical inflation are largely permanent. ${ }^{3}$ While shocks to Transportation can have a significant impact on consumers, there are a variety of methods for hedging these shocks - for example, public transportation, carpooling, or choosing less discretionary travel. ${ }^{4}$ Another often discussed consumer good whose inflation outpaces aggregate inflation is Education. However, one can manage education expenses over time by saving in advance or through borrowing. ${ }^{5}$ Housing inflation has an ambiguous effect on consumers due to the asset characteristics associated with housing and one's ability to borrow against housing appreciation. However, even accounting for the recent wide swing in housing prices, the average annual real change in housing prices between 1948 and 2008 is just over onehalf percent; the 95th and 5th percentiles are 11 and $-10 \%$, respectively. Thus, even though Housing appreciation is skewed, it is much less so than medical expenditures. For

\footnotetext{
${ }^{3}$ The transitory nature of Food and Energy prices is why they are removed when "core inflation" is reported.

4 This analysis refers to the direct impact to consumers from transportation expenses. The input costs nature of transportation inflation is embedded within other components of aggregate inflation to the extent transportation expenses get passed on to consumers.

${ }^{5}$ While one can save for incidental medical expenses through medical savings accounts, these funds must be dispersed annually. It is doubtful one can borrow to cover medical expenses, particularly for terminal illnesses.
} 
instance, in 2004 the average annual medical expenditures for individuals ages 19 to 64 were approximately $\$ 4,500$. A single medical event such as a coronary bypass surgery with 10 days of hospital stay can easily cost $\$ 50,000$, or over 10 times the annual average. To be clear, we are not arguing that the idiosyncratic risk to an individual consumer of bearing high medical costs is a priced factor in the market. Rather, the consumer or investor will pay a premium for assets that provide a hedge against medical shocks (i.e., assets that covary positively with medical inflation). The expected return on these assets will reflect this covariance with medical inflation distinct from traditional factors such as the market, SMB, or HML. We confirm this explanation in subsequent sections.

The above discussion illustrates how medical inflation differs from other components of inflation from the standpoint of the individual consumer. Medical inflation is also a unique expense for firms relative to other input costs. Depending on the industry, firms can manage many of the input costs by altering suppliers, changing product mixes, or using formal commodity derivative markets. Managing labor costs - the avenue through which medical inflation bears upon the firm-is more constrained. Firms can alter the capital/labor production mix to some degree, use part-time workers who are not compensated with health benefits, pass the cost onto customers, or relocate internationally. The firm's remaining medical expenses must be borne by the firm in the form of lower cash flows. ${ }^{6}$

Medical expenses (i.e., inflation) are therefore different in magnitude and kind from other consumer and business expenses. The ability of investors to diversify away these expenses - or equivalently, whether the markets differentially price assets that hedge medical inflation-poses an empirical question that the remainder of this paper addresses using a standard factor pricing methodology.

\section{Motivation and literature}

We make three contributions to the literature. First, we present medical inflation as a non-traditional macroeconomic factor for consideration in the context of prior asset pricing theories. Given the economic impact on individuals (consumption) and firms (earnings), health care costs merit consideration as a priced factor. While even recent macroeconomic factor analysis (e.g., Aretz et al. 2010) argues for the use of (unexpected) aggregate inflation as a factor, it does not discuss decomposing aggregate inflation when the aggregate measure fails to price in the various specifications. Our empirical analysis shows that the medical component of inflation is priced; other components (e.g., housing, energy, transportation, food, or education) do not price. We also extend prior empirical work, specifically Flannery and Protopapadakis (2002), by analyzing their macroeconomic factors' performance in a two-pass pricing methodology. Medical inflation still prices in the presence of other macroeconomic variables such as the Producer Price Index, M2 money supply, and housing starts. The

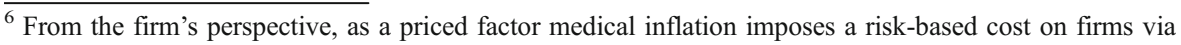
their cost-of-capital. The extent of this cost varies across firms depending on the magnitude of their medical inflation (first-pass regression) betas. One way in which firms might alter their firm-specific risk is to implement programs that incentivize more healthy living (e.g., wellness programs, paid exercise time, or preventive medicine programs). Whether the cost is better borne by each firm in a decentralized fashion or centrally through a social medical care system is another interesting question we leave for future research.
} 
finding that M2 and housing starts are also priced merits consideration for future research, as we do not explore them further here. Finally, we construct a zero net investment portfolio based on the relationship between firm returns and unexpected medical inflation, finding it is priced even in the presence of the more common characteristics-based factors of SMB, HML, and MOM.

Chen et al. (1986) present one of the earliest studies to extend factor pricing beyond the single factor CAPM. Their use of macroeconomic factors, particularly aggregate inflation, provides the initial specification we use to test medical inflation as a unique factor. CRR use the Fama-MacBeth two pass regression method to test a multifactor model which includes the market portfolio as one of the factors. Industrial production, aggregate consumer inflation, and the term and default risk premiums constitute their remaining factors. They find that the market return is not priced in the presence of other macroeconomic factors. However, they find industrial production, default risk premia, and yield curve differentials are priced factors in the multivariate setting, with expected and unexpected aggregate inflation pricing during periods of volatility.

While CRR use economically-based factors, a more contemporary construct includes mimicking portfolios such as the Fama and French (1993) SMB, HML and the Carhart (1997) MOM factors. We test whether the impact of medical inflation is subsumed by these mimicking portfolios, finding that medical inflation is a robustly priced factor across a wide variety of specifications even in the presence of these macroeconomic and characteristic-based factors.

For robustness purposes we also extend a later study, in which Flannery and Protopapadakis (2002) perform the first-pass regression of the Fama and MacBeth (1973) procedure using 17 macroeconomic series. A similar effort by Cenesizoglu (2011) focuses on macroeconomic variables' sensitivity to the business cycle, investigating the daily return effects of news for 21 macroeconomic series. Neither study decomposes inflation into its sub-components, so we extend these findings by (1) including medical inflation as one of several macroeconomic series and (2) performing the associated Fama-MacBeth second-pass regressions. Among others, medical inflation represents a priced factor in the presence of these more recently proposed macroeconomic factors.

In another robustness test, we create a zero net investment portfolio factor by differencing the returns for quintiles of stocks with high and low medical inflation betas. We again find evidence suggesting medical inflation is a priced factor in asset returns; the more common SMB, HML, and MOM factors do not subsume this "medical HML" factor. Finally, we examine other components of aggregate inflation, namely Housing, Energy, Transportation, and Education \& Communication as priced factors in a similar manner to Medical inflation. None of these other components demonstrate universal pricing behavior akin to Medical inflation. Overall, this empirical evidence supports medical care costs as a priced factor.

\section{Medical care inflation data}

Based on when medical care inflation begins its systematic deviation from other inflationary components, our sample begins in January 1985 and ends in August 2009 , for a total of 296 months of data. This sample period represents the time when 
Medical CPI begins a trend of 25 years of month-to-month variation that deviates substantially from aggregate inflation and its other non-Medical components. Explanations vary as to why health care costs begin a dramatic rise starting in the mid1980s, but White (2007) presents data indicating that structural factors in the US drive high health care costs relative to other OECD countries. Specifically, by subdividing the data into pre- and post-1985 time periods, White's study concludes that the relatively late onset of insurance, financing health care costs through private insurers versus a centralized public authority, and a focus on the quality of service versus cost containment all play a role in the relatively high US health care costs.

All series in our study are seasonally-adjusted when possible. All monthly and quarterly percent changes are stationary; the only exceptions are annual Food and Transportation inflation, which exhibit explosive growth in some periods. For the remainder of the analysis we use monthly percent changes for inflation and convert discrete asset returns to their continuous values by differencing the natural log values of the series levels.

We decompose medical inflation into its expected and unexpected components using a Kalman Filter procedure originally described by Ansley (1980) and used in Fama and Gibbons (1982) and as recently as Aretz et al. (2010). Figures 2 and 3 show the plot of ex-post aggregate and medical inflation, respectively, along with their expected counterparts derived using this Kalman Filter method. The expected series are smoothed versions of the respective ex-post inflation series. We construct unexpected inflation as the difference between ex-post inflation and the expected inflation measures from the Kalman Filter.

Table 1 presents the correlations among unexpected medical inflation and other potential factors that could contain the same information such as unexpected

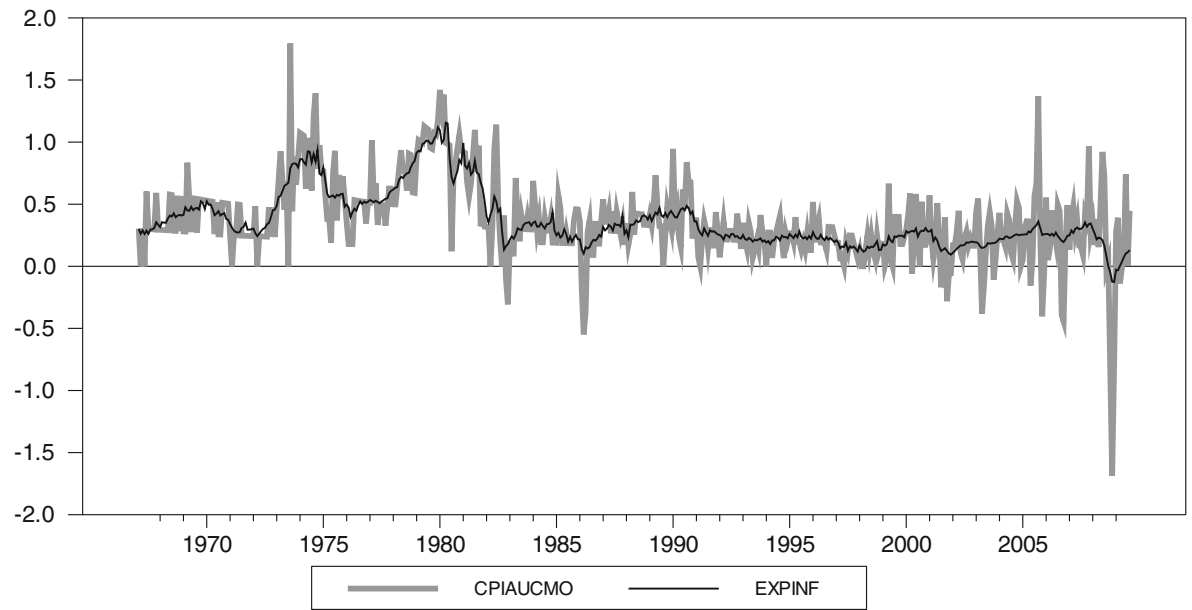

Fig. 2 Ex-post and expected aggregate inflation using Kalman Filter model. This figure shows the time series of ex-post monthly aggregate inflation (CPIAUCMO) versus the expected monthly aggregate inflation $(E X P I N F)$ from January 1967 to August 2009. The expected monthly inflation series is calculated based on the relationship between inflation and interest rates according to a Kalman Filter methodology developed by Ansley (1980) as described in Fama and Gibbons (1982). This procedure permits the constant within a regression model to change dynamically based on past data trends in an effort to discern the difference between the true signal and "noise" associated with the signal. In this analysis, the expected inflation component represents the signal, and the unexpected component is the "noise" 


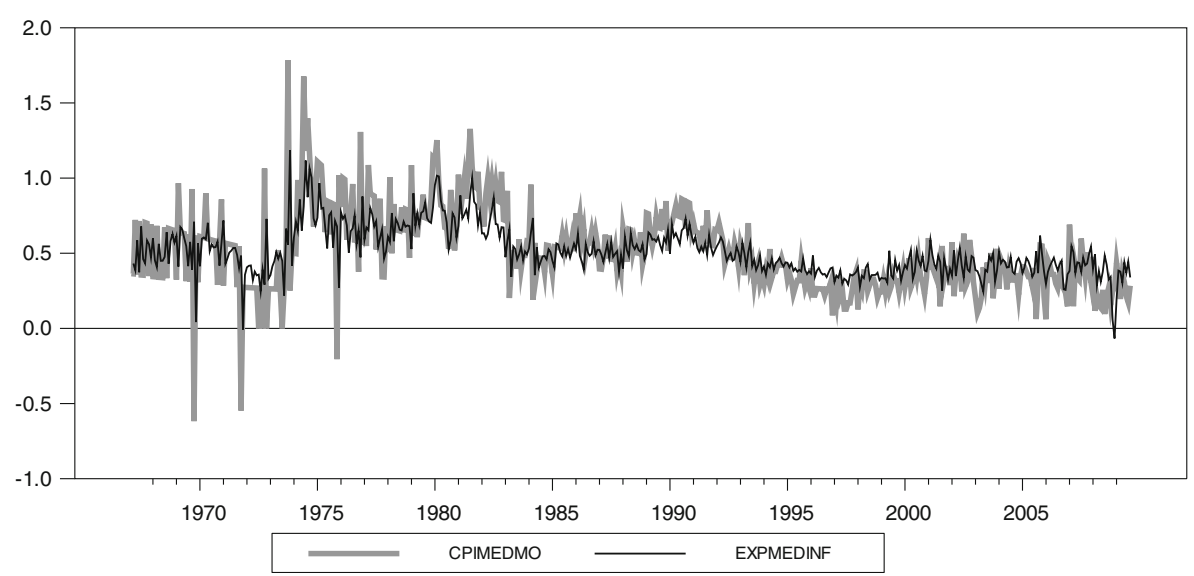

Fig. 3 Ex-post and expected medical inflation using Kalman Filter model. January 1967-August 2009. This figure shows the time series of ex-post monthly medical inflation (CPIMEDMO) versus the expected monthly medical inflation (EXPMEDINF) from January 1967 to August 2009. The expected monthly inflation series is calculated based on the relationship between inflation and interest rates according to a Kalman Filter methodology developed by Ansley (1980) as described in Fama and Gibbons (1982). This procedure permits the constant within a regression model to change dynamically based on past data trends in an effort to discern the difference between the true signal and "noise" associated with the signal. In this analysis, the expected inflation component represents the signal, and the unexpected component is the "noise"

aggregate inflation and the term premium (TERM). Unexpected medical inflation is essentially uncorrelated with unexpected aggregate inflation and with the term premium, with values of -0.014 and 0.029 , respectively. These low correlations provide further evidence that unexpected medical inflation does not simply reflect shocks to aggregate inflation. For subsequent robustness purposes, Table 1 also shows correlation values between unexpected medical inflation and shocks to other components of aggregate inflation, such as housing, energy, transportation, food, or education and communication. These relatively low values indicate medical inflation shocks differ from those of other economic sectors. Additionally, motivated by both the Stock and Watson (2001) vector auto regression (VAR) technique and the Fama and Gibbons (1984) moving average technique, for robustness we also calculate unexpected medical inflation using the residuals from three- to eight-variable VAR specifications and a 6-month trailing moving average. All the proxies for unexpected inflation are highly correlated with each other and importantly, uncorrelated with the other risk factors used in the next section. Additionally, all cross-sectional relationships shown in future tables hold for these various manners of estimating unexpected medical inflation.

\section{Methodology and results}

\subsection{Health care as a priced risk}

In this section we apply a rolling Fama and MacBeth (1973) two-pass methodology to determine whether medical care inflation shocks explain the cross-section of returns across the broader market. We use the 25 size and book-to-market Fama- 


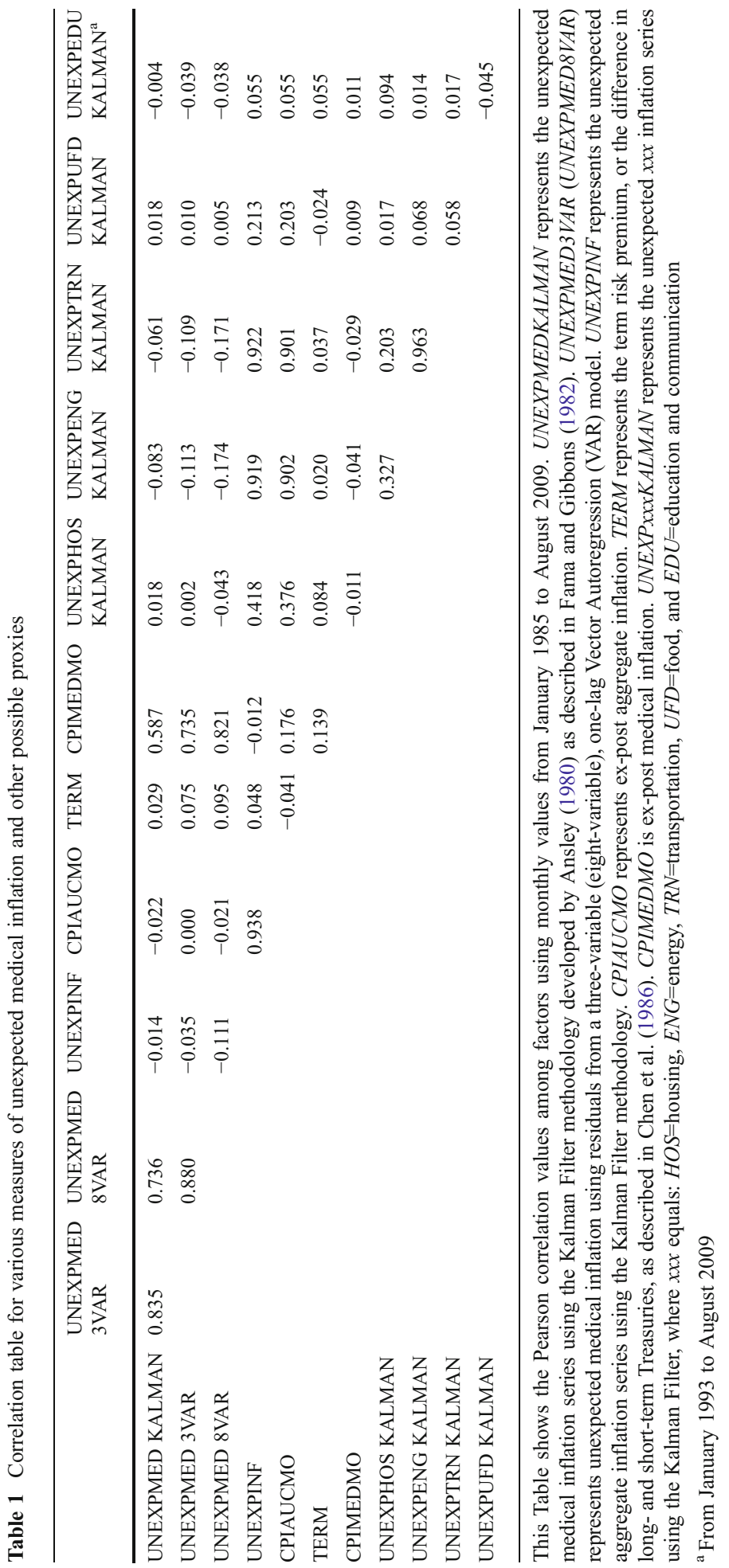


French portfolios as test assets in this analysis. ${ }^{7}$ In addition to market risk, these portfolios capture two features of asset risk that persist across a wide variety of models. In the first pass, we use 60 months of returns to estimate beta values for each of the 25 portfolios. In a single-factor model, for instance, completing this first pass provides 25 beta values. Incorporating additional factors increments the beta count in multiples of 25 (e.g., a three-factor model yields 25 beta values per factor, or 75 total). During the second pass, we run 12 cross-sectional regressions (CSRs) to estimate the monthly price of these betas over the 12 months immediately following the beta estimation period. For example, beginning with 25 Fama and French portfolio beta estimations from January 1980 to December 1984, we estimate 12 monthly crosssectional regressions from January to December 1985. We then increment both the beta estimation period and CSR pricing period by 12 months using the rolling-beta technique (e.g., beta estimation occurs from January 1981 to December 1985 with CSRs occurring from January to December 1986). Using cross-sectional data beginning in January 1985 and ending in August 2009, we obtain 296 monthly risk premium estimates. We then test whether the average risk premium is statistically different from zero or "priced" using the time series of respective risk premia. All risk premia are tested using both the unadjusted standard error and the rolling-beta EIVadjusted asymptotic standard error method described in Shanken (1992a). ${ }^{8}$

We use three major specifications for the first-pass regression. First we augment the CRR (1986) model specifications to include medical inflation components, which results in five total CRR-related specifications. Next, in a hybrid macroeconomiccharacteristics model, we price the Fama and French (1993) five factors, include momentum, and augment these factors with medical inflation for a total of seven related specifications. For macroeconomic robustness, we extend the more recent results of Flannery and Protopapadakis (2002) by including medical inflation to their list of potential macroeconomic factors in five more specifications. Since their study identifies other potential macroeconomic factors, we complete the second-pass factor pricing test for their candidate factors and find that medical inflation shocks remain a priced factor controlling for these additional macroeconomic factors. Finally, for a characteristics-based application, we create a medical inflation factor using return differences between portfolios with high versus low unexpected medical inflation betas. Unexpected medical inflation is a priced factor in every specification it enters, while aggregate medical inflation is priced in all but two of its applicable specifications.

Table 2 presents second-pass results when we augment the CRR (1986) model to include medical inflation as a factor. The specifications represent the CRR baseline

\footnotetext{
${ }^{7}$ We thank Ken French for this data: http://mba.tuck.dartmouth.edu/pages/faculty/ken.french/data library.html.

${ }^{8}$ As a preliminary screen, we decompose the covariance structure of the 25 Fama-French portfolios using principal components analysis. Similar to Chen, Roll and Ross (CRR) (1986), we use the five principal components associated with the five largest eigenvectors to represent the underlying return factor structure. CRR state that "An economic variable is significantly related to stock movements if and only if it is significantly related to at least one of the common stock factors." We regress the five extracted factors against expected medical inflation, the excess market return, SMB, and HML. We strongly reject that the slope coefficient on unexpected medical inflation is jointly zero across the five equations. Unexpected medical inflation is related to the fourth and second principal component at the 0.001 and 0.121 levels, respectively. We proceed with a more in-depth analysis for the remainder of the paper.
} 
Table 2 Macroeconomic factors, two-pass results for priced factors

\begin{tabular}{|c|c|c|c|c|c|}
\hline Specification & 1 & 2 & 3 & 4 & 5 \\
\hline Constant & $1.075^{* * *}$ & $1.071 * * *$ & $1.488 * * *$ & $1.057 * * *$ & $1.679 * * *$ \\
\hline$\triangle E X P M E D$ & & -0.002 & -0.004 & & \\
\hline$U N E X P M E D$ & & $-0.040 * *$ & $-0.040 * *$ & & \\
\hline CPIMED & & & & $-0.040 *$ & $-0.041^{*}$ \\
\hline$M K T R F$ & & & $-1.017 * *$ & & $-1.188 * * *$ \\
\hline$I N D P R O$ & -0.057 & 0.004 & -0.035 & 0.017 & -0.020 \\
\hline$\triangle E X P I N F$ & -0.005 & -0.002 & -0.004 & -0.005 & -0.006 \\
\hline UNEXPINF & 0.023 & 0.027 & 0.026 & 0.026 & 0.010 \\
\hline$D E F$ & $-0.143 * *$ & $-0.153 * *$ & $-0.136^{* *}$ & $-0.138 * *$ & -0.104 \\
\hline TERM & $0.319^{*}$ & $0.326^{*}$ & $0.365^{* *}$ & $0.332 *$ & $0.337 * *$ \\
\hline $\mathrm{N}=$ & 296 & 296 & 296 & 296 & 296 \\
\hline
\end{tabular}

This Table depicts results from the second-pass of the Fama and MacBeth (1973) rolling regression procedure to assess priced risk factors in stock returns. Macroeconomic factors are based on Chen et al. (1986). Results are from the sample period of January 1985 to August 2009 for 296 months' worth of pricing data. The beta estimation period is 60 months. Test assets are the 25 Fama-French quintile-sorted size and book-to-market portfolios. $\triangle E X P M E D$ is the first-differenced series (i.e., time t minus time t-1) of medical inflation. UNEXPMED is the unexpected component of medical inflation as determined by a state space model described in Fama and Gibbons (1982). CPIMED is monthly medical inflation, or the sum of expected and unexpected medical inflation. $M K T R F$ is the market return net of the risk-free rate (taken from Ken French's Data Library). INDPRO is the monthly change in Industrial Production. $\triangle E X P I N F$ is the firstdifferenced series (i.e., time t minus time t-1) of aggregate inflation. UNEXPINF is analogous to $U N E X P M E D$ for aggregate inflation. $D E F$ is the difference between the 10 -year Treasury bond and a portfolio of Baa corporate bonds. TERM is the difference between the 10-year Treasury bond and the 90day Treasury bill. Standard errors (and $p$-values) are EIV-adjusted using the Shanken (1992a) methodology $* * *, * *, *$ indicate significance at the $1 \%, 5 \%$, and $10 \%$ levels

and four model permutations. In the baseline specification (column 1), both the term and default risk premium, $D E F$ and TERM, are priced in support of CRR, while none of the other factors are priced. Column 2 augments the basic CRR model specification, which implements the first-difference of expected aggregate inflation as well as aggregate inflation shocks, with the medication inflation analogs - both the firstdifference of expected medical inflation as well as the unexpected medical inflation series. Unexpected (aggregate) medical inflation prices negatively at the five (ten) percent level even in the presence of (non-priced) expected and unexpected aggregate inflation; both $D E F$ and TERM maintain their pricing. This negative sign on unexpected medical inflation is consistent with the ICAPM hedging role of assets. Assets that covary positively with medical inflation act like a hedge and therefore investors are willing to forego expected return for this hedging benefit. In addition, the magnitude of the coefficient on unexpected medical inflation is similar across the specifications indicating that unexpected medical inflation is nearly orthogonal to the other control variables and measures a distinct priced factor.

Comparable to CRR, specifications 3 and 5 control for the market's influence by including the value-weighted market return premium $(M K T R F)$ as a factor. In specification 3, unexpected medical inflation is priced negatively, and it is robust to the inclusion of the market factor. Adding the market factor does not affect the economic 
significance (magnitude of the coefficient) of medical inflation shocks. ${ }^{9}$ Specifications 4 and 5 substitute aggregate ex-post medical inflation (CPIMED) for expected and unexpected medical inflation and find overall ex-post medical inflation also prices significantly (negative), and the magnitude remains similar across specifications. We lose $D E F$ as a priced factor in the final specification that includes CPIMED and $M K T R F$, but only slightly with a $p$-value of 0.119 .

Overall, accounting for medical inflation in the CRR (1986) analysis strengthens the evidence that market participants demand return premia for exposure to medical inflation, and the impact on the expected return of this demand is insensitive to whether we account for the market return or other control variables.

While the prior specification concentrates solely on other macroeconomic factors, the next test involves augmenting, with medical inflation, three model specifications based on the Fama-French SMB and HML return-based factors. Table 3 presents the results of these second-pass regressions. Specification 1 is the baseline specification for a three-factor model. The first three subsequent specifications include both firstdifferenced expected medical inflation and unexpected medical inflation (UNEXPMED) while augmenting the three-factor model with $D E F, T E R M$, and the Carhart (1997) MOM factor. The final three specifications replace expected and unexpected medical inflation with ex-post medical inflation (CPIMED).

As with prior results, unexpected medical inflation and ex-post medical inflation price negatively across all specifications. The economic significance remains similar to earlier findings and supports the hypothesis that the market recognizes the relevance of medical care costs, particularly unexpected ones. Notably, specification 3 shows that unexpected medical inflation is significant in explaining the cross-section of returns at the $1 \%$ significance level. Once again, MKTRF prices negatively over the past 25 years while TERM continues to price positively. Additionally, $H M L$ prices positively across specifications, while in contrast to the earlier CRR (1986) results, $D E F$ fails to price in any of them. Finally, $S M B$ and $M O M$ both fail to price in any specification where they are included. The evidence in Tables 2 and 3 supports unexpected medical inflation as a non-diversifiable source of risk over the past 25 years even in the presence of the well-known Fama and French (1993) and momentum factors.

\subsection{Robustness: additional factor models}

We next extend the work of Flannery and Protopapadakis (2002), who use unexpected shocks to 17 macroeconomic series as candidates for priced risk factors but do not investigate the effect of medical inflation. We focus on the Flannery and Protopapadakis macroeconomic variables that they argue should be most considered in a pricing analysis given their first-pass results. These variables include the monthly

\footnotetext{
$\overline{9}$ The market factor prices significantly (negative) in columns 3 and 5, which while contrary to economic theory, the findings are not unique to our study. For instance, CRR show negatively-signed (insignificant) prices for value-weighted market returns in their overall period and two of three sub-periods, as do Hahn and Lee (2006) for their specifications and time period. Additionally, Fama and French (1992a) show negatively-signed market risk pricing, which becomes statistically significant for individual stocks in the most recent decade of their study, which ends in 1990. The negative pricing for the market portfolio does not appear isolated to a particular time period or study.
} 
Table 3 Characteristics factors, two-pass results for priced factors

\begin{tabular}{|c|c|c|c|c|c|c|c|}
\hline Specification & 1 & 2 & 3 & 4 & 5 & 6 & 7 \\
\hline Constant & $1.197 * * *$ & $1.022 * * *$ & $1.495^{* * *}$ & $1.576^{* * *}$ & $1.172 * * *$ & $1.523 * * *$ & $1.593 * * *$ \\
\hline$\triangle E X P M E D$ & & -0.004 & -0.003 & -0.003 & & & \\
\hline UNEXPMED & & $-0.036 * *$ & $-0.043 * * *$ & $-0.038 * *$ & & & \\
\hline CPIMED & & & & & $-0.041 * *$ & $-0.049 * *$ & $-0.039 *$ \\
\hline MKTRF & $-0.762 * *$ & $-0.558^{*}$ & $-1.026 * * *$ & $-1.105^{* * *}$ & $-0.721 * *$ & $-1.078 * * *$ & $-1.135 * * *$ \\
\hline$S M B$ & -0.037 & -0.022 & -0.014 & -0.004 & -0.024 & -0.016 & -0.006 \\
\hline$H M L$ & $0.379 *$ & $0.367 *$ & $0.339 *$ & $0.332 *$ & $0.370 *$ & $0.345^{*}$ & $0.349 *$ \\
\hline$D E F$ & & & -0.029 & -0.065 & & -0.079 & -0.107 \\
\hline TERM & & & $0.491 * * *$ & $0.439 * *$ & & $0.424 * * *$ & $0.346^{* *}$ \\
\hline$M O M$ & & & & -0.333 & & & -0.163 \\
\hline $\mathrm{N}=$ & 296 & 296 & 296 & 296 & 296 & 296 & 296 \\
\hline
\end{tabular}

This Table depicts results from the second-pass of the Fama and MacBeth (1973) rolling regression procedure to assess priced risk factors in stock returns. Characteristics factors are from Fama and French (1993) and Carhart (1997). Results are from the sample period of January 1985 to August 2009 for 296 months' worth of pricing data. The beta estimation period is 60 months. Test assets are the 25 Fama-French quintile-sorted size and book-to-market portfolios. $\triangle E X P M E D$ is the first-differenced series (i.e., time $\mathrm{t}$ minus time $\mathrm{t}-1$ ) of medical inflation. UNEXPMED is the unexpected component of medical inflation as determined by a state space model described in Fama and Gibbons (1982). CPIMED is aggregate medical inflation, or the sum of expected and unexpected medical inflation. MKTRF is the market return net of the risk-free rate. $S M B$ is calculated by subtracting the return of the decile of the largest stocks - by market capitalization - from the decile of smallest stocks. $H M L$ is calculated by subtracting the return of the stock decile having the lowest book-to-market equity ratio from the decile with the highest book-to-market ratio. See Fama and French (1993) for additional details regarding $M K T R F, S M B$, and $H M L . D E F$ is the difference between the 10-year Treasury bond and a portfolio of Baa corporate bonds. TERM is the difference between the 10-year Treasury bond and the 90-day Treasury bill. MOM is a momentum factor found by subtracting the returns of a stock portfolio having the lowest recent returns from a portfolio having the highest recent returns. $M K T R F, S M B, H M L$, and $M O M$ are from Ken French's Data Library. Standard errors (and $p$-values) are EIV-adjusted using the Shanken (1992a) methodology $* * *, * *, *$ indicate significance at the $1 \%, 5 \%$, and $10 \%$ levels

percentage changes in (aggregate) producer price index for all commodities (PPI $(A g g))$, the producer price index for crude materials (PPI(Crude)), the $M 1$ and $M 2$ money supplies, and total new housing starts (HOUST). We include ex-post aggregate inflation components for control purposes.

Table 4 depicts the results using this subset of the Flannery and Protopapadakis (2002) macroeconomic variables. Specification 1 shows the baseline model, resulting in priced factors that include unexpected aggregate inflation, (UNEXPINF: positive), the producer price index, (PPI(Agg): positive), and $M 2$ money stock (negative). Adding medical inflation components in the second specification shows it prices negatively yet also affects the pricing behavior of the crude materials component of the producer price index, $P P I(C r u d e)$, which also now prices (positively). The third specification removes the crude component due to the risk of redundancy between it and the producer price index for all commodities. Unexpected medical inflation still prices negatively. The results for ex-post medical inflation (CPIMED) in specifications 4 and 5 deviate from those shown earlier. In the aggregate, while still 
Table 4 Macroeconomic factor candidates, two-pass results for priced factors

\begin{tabular}{llllll}
\hline Specification & 1 & 2 & 3 & 4 & 5 \\
\hline Constant & $0.560^{*}$ & $0.631^{*}$ & $0.831^{* *}$ & 0.423 & 0.534 \\
EEXPMED & & 0.004 & 0.003 & & \\
UNEXPMED & & $-0.026^{*}$ & $-0.028^{*}$ & & \\
CPIMED & & & & -0.025 & -0.021 \\
EEXPINF & 0.007 & 0.008 & 0.008 & 0.005 & 0.003 \\
UNEXPINF & $0.051^{*}$ & $0.057^{* *}$ & 0.043 & $0.053^{*}$ & 0.040 \\
PPI (Agg) & $0.215^{* *}$ & $0.281^{* * *}$ & $0.238^{* *}$ & $0.227^{* *}$ & $0.201^{*}$ \\
PPI (Crude) & 0.410 & $1.085^{*}$ & & 0.425 & \\
MI & -0.084 & -0.080 & -0.079 & -0.105 & -0.123 \\
M2 & $-0.108^{* *}$ & $-0.100^{* *}$ & $-0.100^{* *}$ & $-0.117^{* *}$ & $-0.109^{* *}$ \\
HOUST & $-2.905^{* *}$ & $-2.562^{* *}$ & $-2.320^{*}$ & $-2.778^{* *}$ & $-2.893^{* *}$ \\
$\mathrm{~N}=$ & 296 & 296 & 296 & 296 & 296 \\
\hline
\end{tabular}

This Table depicts results from the second-pass of the Fama and MacBeth (1973) rolling regression procedure to assess priced risk factors in stock returns. Macroeconomic factor candidates are from Flannery and Protopapadakis (2002). Results are from the sample period of January 1985 to August 2009 for 296 months' worth of pricing data. The beta estimation period is 60 months. Test assets are the 25 FamaFrench quintile-sorted size and book-to-market portfolios. $\triangle E X P M E D$ is the first-differenced series (i.e., time t minus time t-1) of medical inflation. UNEXPMED is the unexpected component of medical inflation as determined by a state space model described in Fama and Gibbons (1982). CPIMED is aggregate medical inflation, or the sum of expected and unexpected medical inflation. $\triangle E X P I N F$ is the firstdifferenced series (i.e., time t minus time t-1) of aggregate inflation. UNEXPINF is analogous to UNEXPMED for aggregate inflation. PPIAgg (PPICrude) is the monthly change in Producer Price Index for all commodities (crude materials). $M 1(M 2)$ is the monthly change in M1 (M2) Money Stock, seasonally adjusted. HOUST is the monthly change in total new housing starts. The prior 5 series are from the St. Louis Federal Reserve Federal Reserve Economic Database (FRED). MKTRF is the market return net of the riskfree rate from Ken French's Data Library. Standard errors (and p-values) are EIV-adjusted using the Shanken (1992a) methodology

$* * *, * *, *$ indicate significance at the $1 \%, 5 \%$, and $10 \%$ levels

negatively-signed, ex-post medical inflation does not price significantly as it does in earlier specifications. Thus, the behavior of these other macroeconomic factors, while perhaps subsuming aggregated ex-post medical inflation, does not obviate the relevance of medical inflation shocks. Noteworthy is the consistent pricing behavior of both the $P P I(A g g)$ and the $M 2$ money stock. Both of these results present an avenue for future research. Overall, controlling for the Flannery and Protopapadakis (2002) results, we still find evidence that even accounting for these additional macroeconomic factors, unexpected medical inflation remains priced at conventional statistical levels. Risk premia remain approximately the same magnitude as those shown in prior tables, on the order of $0.03 \%$ per month or approximately 36 basis points per year, for a one-unit-change in medical inflation beta.

Even though medical inflation remains priced as a macroeconomic factor alongside the zero net investment portfolios listed previously, we next test whether the pricing phenomenon is sensitive to the form of the medical inflation factor. Instead of using the medical inflation shock as a factor, we form a high-medical beta minus lowmedical beta $(M e d H M L)$ factor and determine whether it is priced in equilibrium. We 
form portfolios of securities based on their covariance with unexpected medical inflation. We pull from CRSP all stocks that have at least 60 months of returns between January 1967 and December 2008, resulting in 16,093 firms. From these we draw a random sample of 3,000 firms. Beginning in January 1980, we perform timeseries regressions of individual firm returns on medical inflation shocks, expected medical inflation, $S M B, H M L, D E F, T E R M$, and $M O M$ for 60 months. We then order the firms based on the resulting beta associated with unexpected medical inflation and use this ordering for the ensuing 12 months. Note that this sorting measures the sensitivity to medical inflation surprises while controlling for return sensitivity to the other factors. We create quintiles of these stocks ordered by unexpected medical inflation beta and calculate an equally-weighted monthly average of returns in each quintile. Differencing the average returns of the high-beta quintile and low-beta quintile forms our MedHML factor. We roll the beta estimation period forward by 12 months and repeat the process. In the end we generate $288 \mathrm{MedHML}$ factors between January 1985 and December 2008.

We incorporate MedHML as a factor in the Fama-MacBeth two-pass procedure to determine whether it is priced. The first-pass results are given in Table 5, Panel A. Although this specification also includes MKTRF, SMB, HML, DEF, TERM, and $M O M$, we present only the values for MedHML. These results indicate that MedHML covaries significantly with the Fama-French 25 portfolio returns for 14 of the 25 portfolios at conventional significance levels. Additionally, the covariance is positive for firms in the smallest quintile and then changes sign as firms grow in size. All else equal, smaller firms correlate more (i.e., more significantly more often) over time with medical inflation shocks than larger firms. The covariance is not as monotonic on the B/M scale; extreme growth (i.e., low B/M) and value (i.e., high B/M) portfolios generally fail to covary significantly with the MedHML factor.

The second-pass results are located in Table 5, Panel B. The result found in earlier specifications persists, as MedHML again prices negatively. Firms that covary positively with medical risk act as hedges and thus sacrifice expected return due to their risk reducing (ICAPM hedging) contribution. ${ }^{10}$ The market prices a zero investment medical inflation risk factor similarly to how it prices the macroeconomic medical inflation measure, that is, with a negative premium. Thus our finding of the market pricing the risk associated with health care costs is robust to creating a firm characteristics-based factor in addition to the macroeconomic factor analyzed earlier.

\subsection{Robustness: other inflation components}

A natural follow-up question is whether the negative risk premium associated with medical inflation is unique to medical inflation shocks or whether it also occurs with

\footnotetext{
${ }^{10}$ We examined the relationship between medical inflation and the health care industry. Time series regressions over the sample period in this study show significantly negative relationships between medical inflation shocks and returns to firms in the health care industry. The same relationship holds for the pharmaceuticals sub-industry, which represents approximately $80 \%$ of the larger health care industry. Health services (7\%) and medical equipment (13\%) represent the balance of the larger health care industry. All of these time series regressions control for the market risk premium, SMB, HML, MOM, DEF, TERM, and aggregate inflation factors. Health care industry and sub-industry results are the 5- and 48-industry return series, respectively, found in Ken French's data library. Results are available upon request.
} 
Table 5 Characteristics-based medical inflation factor

\begin{tabular}{|c|c|c|c|c|c|c|}
\hline \multirow{2}{*}{\multicolumn{2}{|c|}{ Parameter values }} & \multicolumn{5}{|l|}{ Size } \\
\hline & & Small & 2 & 3 & 4 & Big \\
\hline \multicolumn{7}{|c|}{ Panel A: First-Pass Results for $\beta_{\text {MedHML }}$, January 1985-December 2008} \\
\hline \multirow[t]{5}{*}{$\mathrm{B} / \mathrm{M}$} & Low & 16.49 & -2.40 & -2.40 & -0.48 & -2.99 \\
\hline & 2 & 5.22 & -10.25 & -4.41 & -8.00 & -7.45 \\
\hline & 3 & 1.49 & -5.02 & -7.84 & -6.12 & -4.09 \\
\hline & 4 & 4.52 & -7.68 & -5.73 & -8.80 & -1.25 \\
\hline & High & 5.95 & -7.21 & -3.02 & -0.79 & 4.39 \\
\hline \multicolumn{7}{|c|}{ T-Statistics } \\
\hline \multirow[t]{5}{*}{$\mathrm{B} / \mathrm{M}$} & Low & 4.07 & -0.81 & -0.84 & -0.18 & -1.34 \\
\hline & 2 & 1.78 & -3.76 & -1.42 & -2.48 & -2.67 \\
\hline & 3 & 0.62 & -1.98 & -2.66 & -1.86 & -1.31 \\
\hline & 4 & 1.79 & -3.06 & -2.00 & -3.03 & -0.48 \\
\hline & High & 2.26 & -2.75 & -0.88 & -0.22 & 1.08 \\
\hline \multicolumn{7}{|c|}{ Panel B: Second-Pass Results, January 1985-December 2008} \\
\hline \multicolumn{2}{|c|}{ Constant } & \multicolumn{5}{|c|}{$1.882 * * *$} \\
\hline \multicolumn{2}{|c|}{ MedHML } & \multicolumn{5}{|c|}{$-0.006^{*}$} \\
\hline \multicolumn{2}{|c|}{ MKTRF } & \multicolumn{5}{|c|}{$-1.286^{* * *}$} \\
\hline \multicolumn{2}{|l|}{$S M B$} & \multicolumn{5}{|l|}{0.019} \\
\hline \multicolumn{2}{|l|}{$H M L$} & \multicolumn{5}{|c|}{$0.483^{* *}$} \\
\hline \multicolumn{2}{|l|}{$D E F$} & \multicolumn{5}{|l|}{0.103} \\
\hline \multicolumn{2}{|l|}{ TERM } & \multicolumn{5}{|l|}{0.122} \\
\hline \multicolumn{2}{|l|}{ MOM } & \multicolumn{5}{|c|}{$1.667 * * *$} \\
\hline \multicolumn{2}{|l|}{$\mathrm{N}=$} & \multicolumn{5}{|l|}{288} \\
\hline
\end{tabular}

This Table depicts the factor pricing results using a characteristics-based medical inflation factor for the period January 1985 to December 2008. Panel A shows results for the Fama and MacBeth (1973) first-pass regression for the following model: $R_{p, t}=\alpha_{0}+\sum_{i=1}^{k} \beta_{p, i} Z_{i, t}+u_{t}$ where $R_{p, t}$ is the montht excess return on portfolio $p, p=1$, $\ldots, 25, t$ represents time, $k$ represents the number of factors, and $Z_{i}$ represents a factor used to explain returns. $\beta_{p, i}$ represents a portfolio-specific parameter estimated in the model and is calculated as the covariance of the factor and portfolio return normalized by the variance of the factor (i.e., $\beta_{p, i}=\operatorname{cov}\left(R_{(p, i)}, Z_{i}\right) / \operatorname{var}\left(Z_{i}\right)$. Panel B depicts results from the second-pass of the Fama and MacBeth (1973) rolling regression procedure to assess priced risk factors in stock returns for the overall period and two sub-periods. For this specification, the portfolios $p$ are the Fama and French size- and book-to-market sorted quintiles, $t$ represents the 288 months spanning from January 1985 to December 2008, and the factors $k$ are described as follows. MedHML is the return formed by subtracting the returns of a portfolio having a low beta with medical inflation from the returns of a portfolio having a high beta with medical inflation. These portfolios are formed by sorting individual stocks into quintiles based on their medical inflation beta. The estimated values are shown in the upper table, and the by-portfolio t-statistics are shown in the lower table. The following factors, while included, are not displayed: MKTRF is the market return net of the risk-free rate. $S M B$ is calculated by subtracting the return of the decile of the largest stocks - by market capitalization - from the decile of smallest stocks. $H M L$ is calculated by subtracting the return of the stock decile having the lowest book-to-market equity ratio from the decile with the highest book-to-market ratio. See Fama and French (1993) for additional details regarding MKTRF, $S M B$, and $H M L . D E F$ is the difference between the 10-year Treasury bond and a portfolio of Baa corporate bonds. TERM is the difference between the 10-year Treasury bond and the 90-day Treasury bill. MOM is a momentum factor found by subtracting the returns of a stock portfolio having the lowest recent returns from a portfolio having the highest recent returns. Shading indicates parameters that are significant at the $10 \%$ level. In Panel B $p$-values are below parameter values $* * *, * *, *$ indicate significance at the $1 \%, 5 \%$, and $10 \%$ levels 
other CPI components. Table 6 summarizes the results for medical inflation and other CPI components, namely Housing, Energy, Transportation, Food, and Education and Communication. This last component becomes available beginning in January 1993, while the others have remained CPI components for the entire January 1985 to August 2009 period. We select two specifications from each of Tables 3, 4 and 5 to summarize the results, using the same Kalman Filter method as with Medical inflation to extract the respective shocks to the various other inflation components.

While medical inflation prices negatively in all specifications, at best, Transportation inflation prices in three of the specifications during this same post-1985 period. The sign remains consistently and counterintuitively-from the ICAPM hedging perspective-positive for Transportation inflation. There is little evidence for Food inflation pricing negatively, but none of the other inflationary component shocks show signs of pricing in the past 25 years. The Education and Communication result is somewhat surprising given this inflationary component outpaces aggregate inflation during its (shorter) period of existence, much like Medical inflation. However, we posit these shocks are not as demand inelastic as health care in that individuals have real options when it comes to Education consumption (i.e., delay or abandon getting a degree) that will allow them to smooth consumption in a manner that trivializes the impact on required asset returns.

Given the impact of medical inflation on asset returns in the US, one area of future research would be to find investable assets that act as a hedge against medical inflation. Jennings et al. (2009) begin such an investigation. Counter-intuitively, they find that health care-focused mutual funds are not natural hedges for medical inflation. Payne (2010) implements an iterative Genetic Algorithm approach to find parsimonious hedging portfolios of individual stocks and bonds. Although the outof-sample results are encouraging, more extensive analysis appears warranted. Consistent with prior studies related to aggregate inflation, no particular industries or firm

Table 6 Summary of second-pass results for various types of inflation

\begin{tabular}{lllllll}
\hline $\begin{array}{l}\text { Unexpected } \\
\text { xxx Inflation: }\end{array}$ & $\begin{array}{l}\text { CRR (86) } \\
\text { no MKTRF } \\
\text { (Table 2, } \\
\text { column 2) }\end{array}$ & $\begin{array}{l}\text { CRR (86) } \\
\text { incl MKTRF } \\
\text { (Table 2, } \\
\text { column 3) }\end{array}$ & $\begin{array}{l}\text { FF (93) } \\
\text { no MOM } \\
\text { (Table 3, } \\
\text { column 3) }\end{array}$ & $\begin{array}{l}\text { FF (93) } \\
\text { incl MOM } \\
\text { (Table 3, } \\
\text { column 4) }\end{array}$ & $\begin{array}{l}\text { FP (02) incl } \\
\text { PPI(Crude) } \\
\text { (Table 4, } \\
\text { column 2) }\end{array}$ & $\begin{array}{l}\text { FP (02) no } \\
\text { PPI(Crude) } \\
\text { (Table 4, } \\
\text { column 3) }\end{array}$ \\
\hline $\begin{array}{l}\text { Medical } \\
\text { Housing }\end{array}$ & Negative & Negative & Negative & Negative & Negative & Negative \\
$\begin{array}{l}\text { Energy } \\
\text { Transportation }\end{array}$ & - & - & - & - & - & - \\
Food & - & - & - & - & - & - \\
Education \& & - & - & Positive & Positive & Positive & - \\
Communication & & - & Negative & - & - & - \\
\hline
\end{tabular}

This Table depicts the statistically-significant (10\% level) unexpected components and signs of various inflation series in the US for the period January 1985 to August 2009 using OLS standard errors. The model specifications correspond to the indicated studies and our earlier Tables. CRR refers to Chen et al. (1986), FP refers to Flannery and Protopapadakis (2002), and FF refers to Fama and French (1993). The two-pass pricing methodology follows Fama and MacBeth (1973)

${ }^{a}$ Results for pricing period January 1998-August 2009 since data series begins January 1993 
types consistently hedge medical inflation. Another area for future research includes health care's role as a priced factor in other countries. Such international comparisons are useful in assessing the robustness of underlying investor attributes across countries and cultures. While medical inflation contrasts with these underlying attributes due to its entanglement with institutional structures and the delivery of medical services that are unique to many countries, cross-country comparisons could help identify which institutional structures drive the results in this paper.

\section{Conclusion}

Health care represents a major component of the US economy. In the past quartercentury its costs have risen much faster than the balance of the economy as measured by the CPI. Despite these escalating costs, firms have shown resilience in their commitment to provide medical care as an employee benefit. Even in the presence of medical insurance, catastrophic medical expenses represent a real bankruptcy risk to individuals. Consequently, individuals would price assets that covary positively with medical inflation at a premium due to their hedging benefit. In addition, to the extent firms are exposed to medical costs differently (i.e., more or less employees, better or worse health care plans, more or less leverage when negotiating rates with providers), their cash flows change as this component of their cost structure changes. And if investors cannot diversify away this risk across firms, they will demand excess returns for bearing the risk of escalating medical expenses that firms evidently will not or cannot trim.

This study sheds light on whether the US stock market considers medical care costs a source of non-diversifiable risk. By separating the medical inflation component from the other basket of goods that composes aggregate inflation, we generate a macroeconomic factor to test these questions. Looking at monthly returns for the period between January 1985 and August 2009, we use the earlier factor model by Chen et al. (1986) as a baseline to show medical inflation's behavior in the cross-section. We also expand the analysis to incorporate the findings regarding macroeconomic factors from Flannery and Protopapadakis (2002) as well as the mimicking factors developed in Fama and French (1993). We augment these models to include an expected and unexpected medical inflation component. Our findings support the contention that (unexpected) medical inflation represents a priced risk factor over the past 25 years and commands a risk premium of between 31 and 51 basis points per annum per unit change in beta. We also show that a mimicking factor based on stock returns' relationship with medical inflation also explains the cross-section of returns over this period. Finally, we find this relationship is unique to the medical component of inflation, as neither aggregate inflation nor any of its other components significantly explain the cross-section of returns as consistently as the medical component. Due to its role in the US economy and - as we findin the US stock market, it is no surprise the health care industry receives the high level of political and popular attention that it does.

Acknowledgments We thank Richard DeFusco, Donna Dudney, Geoffrey Friesen, Gordon Karels, and anonymous referees for their constructive comments. Any remaining errors are our own. The opinions included are those of the authors and not necessarily those of the U.S. Air Force Academy, the U.S. Air Force, or any other federal agency. 


\section{References}

Ansley CF (1980) Signal extraction in finite series and the estimation of stochastic regression coefficients, Proceedings of the American Statistical Association (Business and Economic Statistics Section)

Aretz K, Bartram SM, Pope PF (2010) Macroeconomic risks and characteristic-based factor models. J Bank Financ 34:1383-1399

Bodie Z (1976) Common stocks as a hedge against inflation. J Finance 31:459-470

Boudoukh J, Richardson M (1993) Stock returns and inflation: a long-horizon perspective. Am Econ Rev $83: 1346-1355$

Carhart MM (1997) On persistence in mutual fund performance. J Finance 52:57-82

Cenesizoglu T (2011) Size, book-to-market ratio and macroeconomic news. J Empir Financ 18:248-270

Chen N-F, Roll R, Ross SA (1986) Economic forces and the stock market. J Bus 59:383-403

Fama EF (1981) Stock returns, real activity, inflation and money. Am Econ Rev 71:545-565

Fama EF, French KR (1992) The cross-section of expected stock returns. J Finance 47:427-465

Fama EF, French KR (1993) Common risk factors in the returns on stocks and bonds. J Financ Econ 33:3-56

Fama EF, Gibbons MR (1982) Inflation, real returns, and capital investment. J Monet Econ 9:297-323

Fama EF, Gibbons MR (1984) A comparison of inflation forecasts. J Monet Econ 13:327-348

Fama EF, MacBeth J (1973) Risk, return and equilibrium: empirical tests. J Polit Econ 81:607-636

Fama EF, William Schwert G (1977) Asset returns and inflation. J Financ Econ 5:115-146

Flannery MJ, Protopapadakis AA (2002) Macroeconomic factors do influence aggregate stock returns. Rev Financ Stud 15:751-782

Geske R and Roll R (1983) The fiscal and monetary linkages between stock returns and inflation. J Financ March 1-33

Hahn J, Lee H (2006) Yield spreads as alternative risk factors for size and book-to-market. J Financ Quant Anal 41:245-269

Himmelstein DU, Thorne D, Warren E, Woolhandler S (2009) Medical bankruptcy in the United States, 2007: results of a national study. Am J Med 122:741-746

Jennings WW, Fraser SP, Payne BC (2009) Do health care investments hedge health care liabilities? J Invest 18(1):69-74

Lintner J (1965) The valuation of risk assets and the selection of risky investments in stock portfolios and capital budgets. Rev Econ Stat 47:13-37

Modigliani F, Cohn R, Inflation, Rational Valuation, and the Market (1979) Financ Anal J 35:22-44

Payne BC (2010) Two Essays on health care costs and asset returns. Dissertation, University of Nebraska

Ross SA (1976) The arbitrage theory of capital asset pricing. J Econ Theory 13:341-360

Schwert GW (1981) The adjustment of stock prices to information about inflation. J Finance 36:15-29

Shanken J (1992) On the estimation of beta-pricing models. Rev Financ Stud 5:1-33

Sharpe WF (1964) Capital asset prices: a theory of market equilibrium under conditions of risk. J Finance $19: 425-442$

Stock JH, Watson MW (2001) Vector autoregressions. J Econ Perspect 15:101-115

White C (2007) Health care spending growth: how different is the United States from the rest of the OECD? Heal Aff 26:154-161 